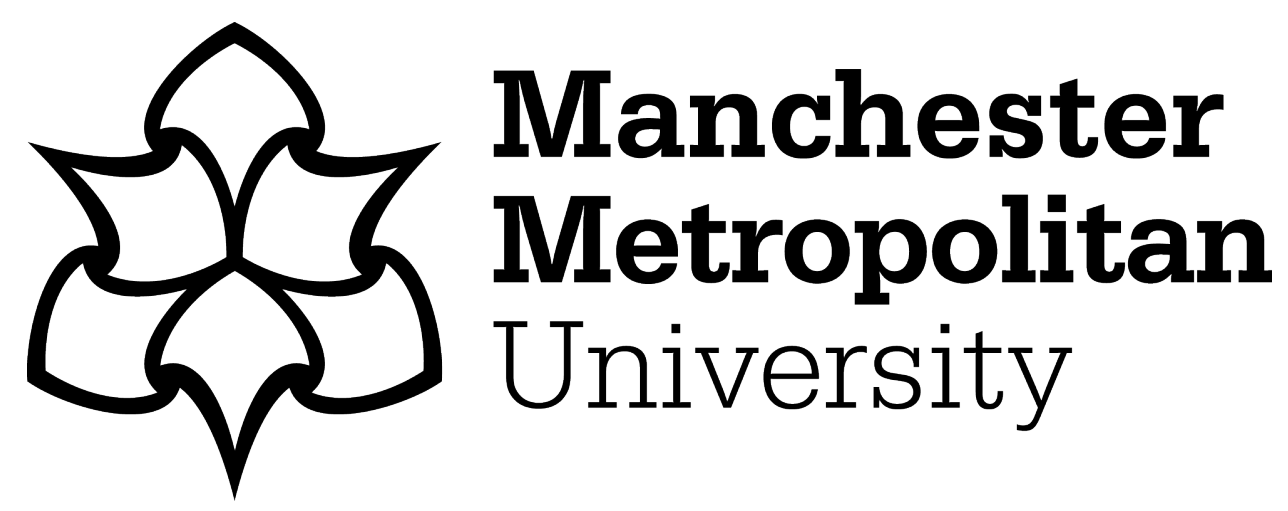

Beake, BD, Isern, L, Endrino, JL, Liskiewicz, TW and Shi, X (2021) Microscale impact resistance of coatings on hardened tool steel and cemented carbide. Materials Letters, 284. ISSN 0167-577X

Downloaded from: https: //e-space.mmu.ac.uk/627030/

Version: Accepted Version

Publisher: Elsevier

DOI: https://doi.org/10.1016/j.matlet.2020.129009

Usage rights: Creative Commons: Attribution-Noncommercial-No Derivative Works 4.0

Please cite the published version 


\title{
Micro-scale impact resistance of coatings on hardened tool steel and cemented carbide
}

\author{
B.D. Beake ${ }^{1, *}$, L. Isern ${ }^{2}$, J.L. Endrino ${ }^{3,4}$, T.W. Liskiewicz ${ }^{5}$, X. Shi $^{6}$
}

1 Micro Materials Ltd, Willow House, Yale Business Village, Ellice Way, Wrexham, LL13

$$
\text { 7YL, UK }
$$

2 School of Aerospace, Transport and Manufacturing, Cranfield University, Bedford, MK43

$$
\text { OAL, UK }
$$

3 IKERBASQUE, Basque Foundation for Science, Maria Diaz de Haro 3, 48013 Bilbao, Spain

4 Basque Center for Materials, Applications \& Nanostructures, UPV/EHU Science Park, 48940 Leioa, Spain

5 Faculty of Science and Engineering, Manchester Metropolitan University, John Dalton Building, Charles Street, Manchester M15 6BH, UK

6 College of Mechanics and Materials, Hohai University, Nanjing 210098, China

* Corresponding author. Email: ben@micromaterials.co.uk

Keywords:- thin films, physical vapour deposition, fatigue, wear and tribology.

\begin{abstract}
Micro-impact, a novel accelerated test method for assessing coating durability under repetitive contact, has been developed to concentrate impact-induced stresses close to the interfaces in coating systems. Test results are described for carbon coatings on hardened tool steel and nitride-based coatings on cemented carbide. At higher load it was possible to show the increasing contribution of the substrate properties (load support and ductility) to the
\end{abstract}


coating system response whilst retaining high sensitivity to the coating properties. Hard and elastic carbon coatings on hardened tool steel displayed very low impact resistance under these conditions. Relatively soft carbon-based coatings with more metallic character and high plasticity (low $H / E$ ) deposited on hard but tough tool steel were resistant to radial cracking and lateral fracture at high load. Lateral fracture at high load and extensive substrate cracking was observed at higher load for hard nitrides on cemented carbide. The micro-impact test has the potential to significantly speed up the pace of coating system selection for durability under highly loaded repetitive contacts, as occur in coatings applications in engine components and in discontinuous cutting operations.

\section{Introduction}

Resistance to repetitive impact is critical for many applications of coatings, including engine components and discontinuous cutting operations such as milling [1-3]. Cyclic impact tests have revealed deformation mechanisms not observed in single-cycle tests [4] and have been used as model tests for determining coating durability $[1,3,5,6]$. Deformation and failure mechanisms depend on applied load and indenter sharpness [7]. In macro-scale impact tests using mm-sized WC indenters at small $t / R$ ( $t=$ coating thickness, $R=$ indenter radius $)$, the stresses for plasticity are far into the substrate and the fatigue behaviour is influenced by substrate properties $[1,8-10]$. Knotek reported that $\mathrm{CrN}$ coatings had improved impact resistance when deposited on tool steel in comparison to hard metal substrate [1]. Rapid nano-impact tests with sharp cube corner diamond indenters at higher $t / R$ are very sensitive to small changes in coating brittleness and have shown excellent correlation to coating performance in applications [3]. To fill the gap between these ranges, the micro-impact test has been developed as a fully instrumented accelerated technique sensitive to coating and substrate together where stresses can be concentrated near interface(s) in the system [11-12]. A nanomechanical system has been adapted to monitor impact-induced surface damage 
produced by repetitive high strain rate impacting with a diamond probe as described in [1112]. In this letter we have directly compared the impact behaviour of coatings on hardened tool steel (HTS) and cemented carbide (hard metal, HM) substrates to determine the linkages between (1) substrate ductility, (2) substrate load carrying capacity and resultant coating bending strains (3) on impact resistance and failure mechanisms, and also to propose key test metrics for assessing coating durability. The coating-substrate systems were chosen for their industrial relevance in engine applications and high performance metal cutting.

\section{Materials and methods}

Carbon coatings were graded $\mathrm{C} / \mathrm{Cr}$ and graded a-C:H deposited on hardened M42 steel (Graphit-IC and Dymon-IC from Teer Coatings) and WC/C (a-C:H:W with CrN sublayer) on hardened M2 steel (Balinit C Star from Oerlikon Balzers). The TiAlN-based coatings were $\mathrm{Ti}_{0.25} \mathrm{Al}_{0.65} \mathrm{Cr}_{0.1} \mathrm{~N}$ and $\mathrm{Ti}_{0.1} \mathrm{Al}_{0.70} \mathrm{Cr}_{0.2} \mathrm{~N}$ (Kobelco), all deposited on WC-5wt.\% Co HM substrate (Sandvik).

Micro-impact tests were performed with a NanoTest Vantage (Micro Materials Ltd.) with spheroconical diamond indenters of end radii 17-20 $\mu \mathrm{m}$ and coil forces of 500-2500 $\mathrm{mN}$. The applied loads were chosen to produce a range of load- and coating- dependent impact deformation response within the short test duration. The probe was retracted $40 \mu \mathrm{m}$ away from the sample surface and rapidly accelerated to the surface to produce each impact. The test duration was $300 \mathrm{~s}$ with 1 impact every $4 \mathrm{~s}$. Every test was repeated 3-5 times. Hardness $(H)$ and elastic modulus $(E)$ were determined by nanoindentation (NanoTest system, Micro Materials Ltd.) and are summarised in the Table, along with the coating thickness $\left(\mathrm{t}_{\mathrm{f}}\right)$.

Table. Mechanical properties of coatings and substrates

\begin{tabular}{|l|l|l|l|l|l|}
\hline Sample & $\mathrm{t}_{\mathrm{f}}(\mu \mathrm{m})$ & $H(\mathrm{GPa})$ & $E(\mathrm{GPa})$ & $H / E$ & $H^{3} / E^{2}(\mathrm{GPa})$ \\
\hline
\end{tabular}




\begin{tabular}{|c|c|c|c|c|c|}
\hline $\mathrm{C} / \mathrm{Cr}$ & 2.5 & $13.9 \pm 4.0$ & $182 \pm 47$ & 0.077 & 0.082 \\
\hline $\mathrm{a}-\mathrm{C}: \mathrm{H}$ on M42 & 2.8 & $17.0 \pm 3.6$ & $140 \pm 24$ & 0.122 & 0.25 \\
\hline $\mathrm{WC} / \mathrm{C}$ & 3.0 & $11.5 \pm 0.9$ & $161 \pm 7$ & 0.071 & 0.059 \\
\hline TiAl70CrN & 1.6 & $27.5 \pm 6.5$ & $467 \pm 62$ & 0.059 & 0.095 \\
\hline TiAl65CrN & 2.5 & $27.8 \pm 1.5$ & $445 \pm 26$ & 0.062 & 0.108 \\
\hline HM & (bulk) & $19.1 \pm 1.2$ & $642 \pm 26$ & 0.030 & 0.017 \\
\hline HTS & (bulk) & $12 \pm 1$ & $210 \pm 20$ & 0.057 & 0.039 \\
\hline
\end{tabular}

\section{Results and Discussion}

Under the applied loads and probe sharpness used, the micro-impact tests represent severe contact conditions for the coatings so that failures occur within the 5 min test duration even with the HTS and HM substrates which provide strong load support to the coatings. In comparison, when carbon coatings were deposited on softer substrates such as non-hardened M2 steel or 316 L stainless steel, complete coating failure occurred on initial impact at lower load than was used in this study [13].

SEM images in Figure 1 illustrate the major impact-induced cracking behaviours observed. Cracking was concentrated at the periphery of the impact craters where tensile stresses were highest. There was extensive lateral fracture from $500-750 \mathrm{mN}$ for the a-C:H coating on HTS, which can expose the Cr bond layer (as in EDX analysis in fig.1(a) inset). Ring cracking was observed on the $\mathrm{WC} / \mathrm{C}$ and $\mathrm{C} / \mathrm{Cr}$ coatings, with radial cracking from 1000 and $1750 \mathrm{mN}$ respectively but lateral cracking was not observed to $2000 \mathrm{mN}$ (fig. 1(b)) which was the highest load used for the carbon coatings. The coatings on HM showed ring and radial cracking from $750 \mathrm{mN}$ (fig. 1(c)). Lateral coating fracture with extensive substrate fracture 
(fig. 1(d)) occurred at higher load, from $750-1000 \mathrm{mN}$ on $\mathrm{Ti}_{0.10} \mathrm{Al}_{0.70} \mathrm{Cr}_{0.2} \mathrm{~N}$ and from 1500 $1750 \mathrm{mN}$ on $\mathrm{Ti}_{0.25} \mathrm{Al}_{0.65} \mathrm{Cr}_{0.1} \mathrm{~N}$.

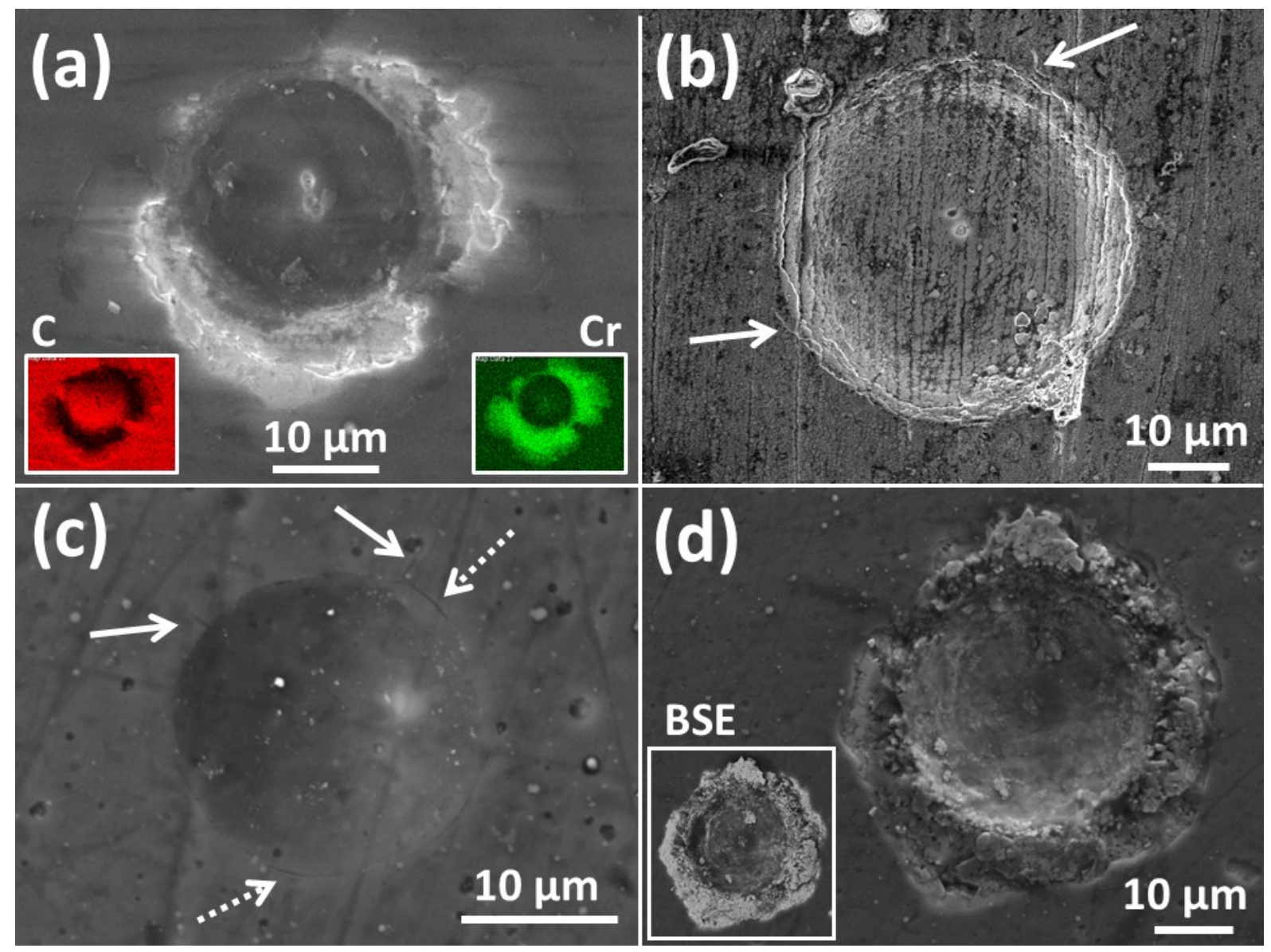

Figure 1 SEM images of (a) $750 \mathrm{mN}$ a-C:H with EDX maps shown in insets - $C$ (red) and $C r$ (green); (b) $2000 \mathrm{mN} \mathrm{C/Cr}$; (c) $750 \mathrm{mN}$ TiAl70CrN; (d) $2250 \mathrm{mN}$ TiAl70CrN (inset BSE image). Full arrows - small radial cracks in (b,c); dotted arrows - single ring crack in (c).
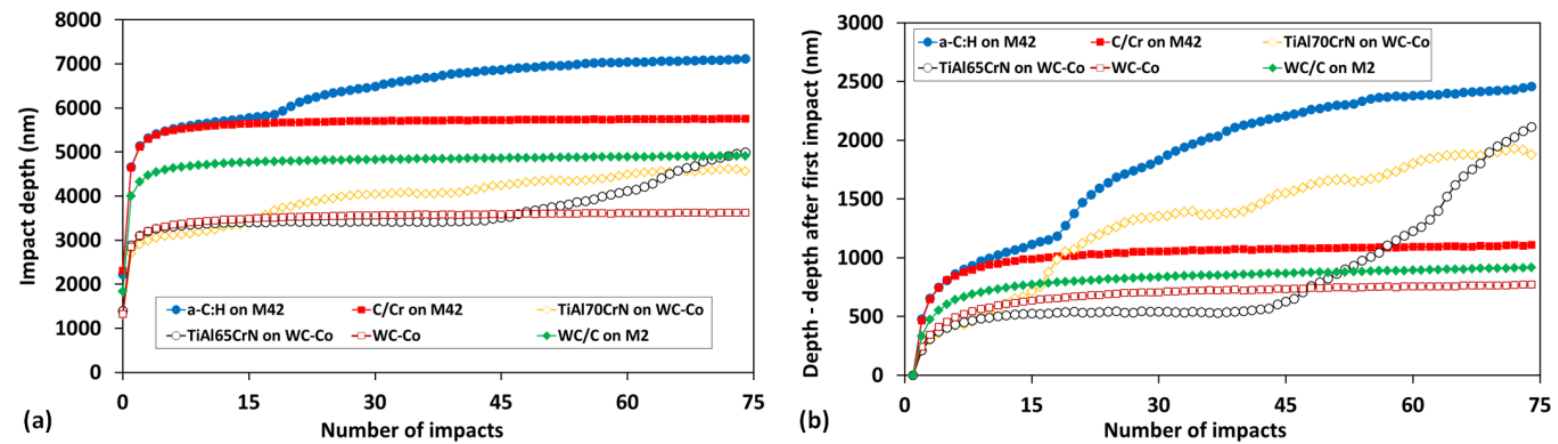

Figure 2 (a) impact depth and (b) depth change vs. impact cycles at $1500 \mathrm{mN}$ 
Further information is provided by monitoring the impact depth during the test. Figure 2 (a) shows typical probe depth data during $1500 \mathrm{mN}$ tests. Most of the plastic deformation and the circumferential/radial cracking (if present) occurred during the first impact [14]. Subsequent cycle-by-cycle evolving coating damage can be more clearly shown by replotting data as depth changes (i.e. [depth - depth after first impact]) as in fig. 2(b). On continued impact, there was a gradual increase in depth due to plasticity which reduced as contact approached fully elastic behaviour and the depth approached a plateau before lateral cracking due to fatigue. When lateral fracture occurred, the final depth change (final impact depth - depth after first impact) was higher irrespective of substrate (fig. 2(b)).

As shown in the Table, the HM substrate is harder and stiffer than HTS and provided greater load carrying capacity and therefore lower deformation shown by smaller initial depths in fig. 2(a). The carbon coatings were subjected to higher bending strains on HTS. The a-C:H has low plasticity (high $H / E$ ) and was too brittle, undergoing lateral fracture from $750 \mathrm{mN}$. In contrast, the softer $\mathrm{C} / \mathrm{Cr}$ and $\mathrm{WC} / \mathrm{C}$ coatings, with more metallic character and higher plasticity were markedly more resistant to radial cracking and lateral fracture.

Lateral fracture was unavoidable at high load for the harder coatings on HM. Fig. 3 (a) shows the load dependence of the mean and standard deviation of the depth increase through the test ([final depth - depth after first impact]). For the three coatings susceptible to lateral fracture, the number of impacts required to produce it are shown in fig. 3(b). The effect of the lower ductility of the HM substrate was more apparent for thinner coatings and/or at higher load. At low load the HM provides enhanced load carrying capacity but as the load increased the number of impacts required to cause lateral fracture reduces and on the TiAl70 $\mathrm{CrN}$ is then lower than that on a-C:H due to the limited ductility of the HM substrate and lower coating thickness. The break-up of the carbide skeleton resulted in abrupt depth reductions 
prior to transition to faster damage rate and further increases as the test progressed (neither of which were observed on HTS where the depth levelled off after coating failure).
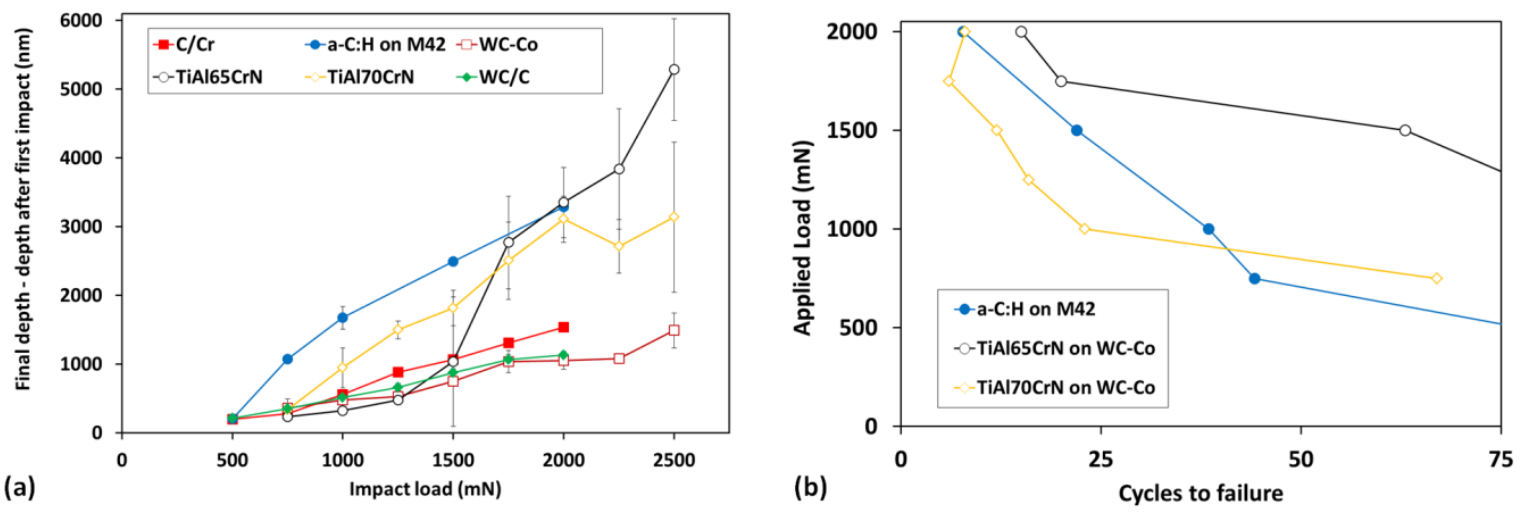

Figure 3 Load dependence of (a) depth increases (b) time-to-lateral fracture (no lateral fracture for $\mathrm{C} / \mathrm{Cr}, \mathrm{WC} / \mathrm{C}$ and $\mathrm{WC}-\mathrm{Co}$ )

HTS is more ductile than HM, which aids damage tolerance of the coating systems at higher load, where on higher plasticity coatings lateral fracture was completely suppressed under the test conditions. The combination of a coating with high plasticity and a tough substrate appears beneficial for impact resistance. Ramirez and co-workers reported enhanced impact resistance for soft $\mathrm{W}$-doped carbon films in comparison to TiN when both were deposited on cold-work steel [8]. For AlCrN coatings, Yang and co-workers noted that, although HM provides better load support and resistance to crack initiation, the tougher tool steel displays better damage tolerance by resisting crack propagation more effectively [9].

\section{Conclusions}

Carbon-based coatings with moderate hardness and high plasticity (low $H / E$ ) on HTS were resistant to radial cracking and lateral fracture in the micro-impact test. Despite the greater load carrying capacity of the HM, substrate lateral fracture at high load and extensive substrate cracking was observed at higher load for all the nitride coatings studied. When 
comparing tests at different applied load or on different substrates, the change in depth after the initial impact can provide a more useful indicator of the extent of coating failure than the final impact depth.

\section{Declaration of Competing Interest}

There are no conflicts to declare.

\section{Acknowledgements}

Funding from Innovate UK (Project No. 132369) and China Scholarships Council (CSC, No. 201706090126) is gratefully acknowledged. JLE thanks the financial support from the Basque Government Industry Department (ELKARTEK Intool2).

\section{References}

1. O. Knotek, B. Bosserhoff, A. Schrey T. Leyendecker, O. Lemmer, S. Esser, Surf. Coat. Technol. 54/55 (1992) 102-107.

2. S.D.A. Lawes, S.V. Hainsworth, M.E. Fitzpatrick, Wear 268 (2010) 1303-1308.

3. K.-D. Bouzakis, F. Flocke, G. Skordaris, E. Bouzakis, S. Geradis, G. Katirtzoglou and S. Makrimallakis, Wear 271 (2011) 783-791.

4. D.K. Kim, Y.-G. Jung, I.M. Peterson, B.R. Lawn, Acta Mater. 47 (1999) 4711-4725.

5. R. Bantle, A. Matthews, Surf. Coat. Technol. $74-75$ (1995) 857-868.

6. K.-D. Bouzakis, A. Siganos, T. Leyendecker and G. Erkens, Thin Solid Films 460 (2004) 181-189.

7. B.R. Lawn, Y. Deng, P. Miranda, A. Parajes, H. Chai, D.K. Kim, J. Mater. Res. 17 (2002) 3019-3036.

8. G. Ramírez, E. Jiménez-Piqué, A. Mestra, M. Vilaseca, D. Casellas, L. Llanes, Tribol. Int. 88 (2015) 263-270. 
9. J Yang, CA Botero, N Cornu, G Ramírez, A Mestra and L Llanes, 2013 IOP Conf. Ser.: Mater. Sci. Eng. 48012003.

10. S.Y. Yoon, S.-Y. Yoon, W.-S. Chung, K.H. Kim, Surf. Coat. Technol. 177-178 (2004) 645-650.

11. B.D. Beake, L. Isern, J.L. Endrino, G.S. Fox-Rabinovich, Wear 418-419 (2019) 102110.

12. B.D. Beake, T.W. Liskiewicz, A. Bird, X. Shi, Tribol. Int. 149 (2020) 105732.

13. S.J. McMaster, B.D. Beake, T.W. Liskiewicz, unpublished data.

14. E.A. Pérez, R.M. Souza, Surf. Coat. Technol. 188-189 (2004) 572-580. 